- REVIEW ARTICLE

Volume 10 Issue 12018

DOI: 10.21315/eimj2018.10.1.2

ARTICLE INFO

Submitted: $10-01-2018$

Accepted: 21-02-2018

Online: 30-03-2018

\section{Comparing and Contrasting Quantitative and Qualitative Research Approaches in Education: The Peculiar Situation of Medical Education}

\author{
Amira Farghaly ${ }^{1,2}$ \\ ${ }^{1}$ Prince Sattam Bin Abdulaziz University, College of Medicine, \\ Al Kharj, SAUDI ARABIA \\ ${ }^{2}$ The Faculty of Medicine, Suez Canal University, Ismailia, EGYPT
}

To cite this article: Farghaly A. Comparing and contrasting quantitative and qualitative research approaches in education: the peculiar situation of medical education. Education in Medicine Journal. 2018;10(1):3-11. https://doi.org/10.21315/eimj2018.10.1.2

To link to this article: https://doi.org/10.21315/eimj2018.10.1.2

\title{
ABSTRACT
}

Research is about trying to discover the world and its phenomena in a systematic and structured manner. Humans have approached research in different ways based on their assumptions about social reality, knowledge, and human nature, namely ontology, epistemology, and methodology. These assumptions gave rise to two poles; quantitative and qualitative research and they have long been viewed as a dichotomy that can never be subject to compromise. This view has slightly changed with the realisation that quantitative and qualitative research can be complementary to each other. This is usually the case when the need for theory emerges and gets realised by qualitative research in order to guide quantitative research. Medical education is a social science that has almost the same categorisation of assumptions about the world. Medical educators and educationists apply both quantitative and qualitative research in order to elucidate some insights about teaching and learning in medicine, and about the best evidence and the best practices that can be applied by healthcare providers and medical educators. The aim of this review is to highlight the main similarities and differences between quantitative and qualitative research approaches/paradigms, present their origins from a historical and philosophical background, and focus on the case of medical education in terms of how it tackles quantitative and qualitative research, and what special attributes of medical education should be taken into consideration while conducting research.

Keywords: Research, Approach, Quantitative, Qualitative, Medical education

Dr. Amira Farghaly, MD, PhD, Prince Sattam Bin Abdulaziz University, College of Medicine, Al Kharj 11942, PO. Box: 173 Saudi Arabia | Emails: am.farghaly@psau.edu. sa / amira.medfomscu@gmail.com

\section{INTRODUCTION}

It is a human nature to try to understand the world and decipher the secrets of its phenomena. People try to understand the nature of phenomena by means of three broad methods; experience, reasoning, and research (1). Understanding life phenomena started with the deductive reasoning, as described by Aristotle, which relied mainly on syllogism, a formal argument in logic that is formed by two statements and a conclusion which must be true if the two statements are true. Then came the inductive reasoning, proposed by Francis Bacon, which introduced the 
idea of generating hypotheses based on observations, and finally the combined inductive-deductive approach which combines Aristotelian deduction with Baconian induction, with back and forth induction and deduction (2).

The ways lay people and scientists approach understanding of the world are different. Lay people rely essentially on haphazard events, and are selective in choosing evidence, while scientists construct theories systematically and test their hypotheses firmly so that their explanations would have firm bases (2).

\section{NATURE OF EDUCATIONAL RESEARCH}

In 1970, Kerlinger defined research as "the systematic, controlled, empirical and critical investigation of hypothetical propositions about the presumed relations among natural phenomena" (3). The concept of research emerged from the inductive-deductive approach. Research can be distinguished from the regular problem solving methods in that it is systematic and controlled, empirical, and self-correcting. Research is viewed as a combination of both experience and reasoning that must be considered as the most successful approach to the discovery of truth, especially as far as the natural sciences are concerned (2).

The thing that distinguishes educational research from other types of rigorous inquiry is the problem on which the research is centred. Ultimately, educational research carries an assumption of benefiting education (4). Educational research has mainly absorbed two views of the social sciences, based on conceptions of social reality. These are the traditional view and the interpretive view. In brief, the traditional view holds that the social sciences are essentially the same as the natural sciences and are concerned with discovering natural laws regulating and determining individual and social behaviour. This view mainly originated from deductive reasoning, also called the top-bottom approach to knowledge. The interpretive view, on the other hand, emphasises how people differ from inanimate natural phenomena and from each other. This view originated from the inductive reasoning, and is also known as the bottom-up approach to knowledge (2).

\section{ONTOLOGY, EPISTEMOLOGY, HUMAN NATURE, AND METHODOLOGY}

Four sets of assumptions about the social world exist. The first set is about the nature of the social phenomena and whether they are external to the individual or a product of individual consciousness. This assumption was of an ontological kind. The second set of assumptions is about epistemology and the knowledge base and how it is communicated and in what form(s). Then, comes a set of assumptions about human nature and the relationship between human beings and their environment, and finally the fourth set of assumptions, which is considered as the result of the former three sets, which is about methodology (5). Since ontology, epistemology, and human nature would determine to a great extent which methods to apply in conducting research, methodology is greatly influenced by those assumptions. Ontological assumptions give rise to epistemological assumptions, which in turn give rise to methodological considerations. Then, methodology influences issues of instrumentation and data collection (6).

\section{Ontology}

Ontology is about asking oneself whether the objects have independent existence or are dependent on the individual, whether the social reality is external to the individual or as result of their consciousness, whether there is a given "out there" in the world or it is created in our minds. This view gives rise to two perspectives or two kinds of people; the nominalist, who views objects of thoughts as words with no independent thing constituting the meaning of the word, 
and the realist, who views objects as having independent existence and not depending on the knower. In other words, the realist is convinced that there is an objective reality that can be discovered by research, by identifying the most important "parts" or variables, and trying to find out how they relate to each other. On the other hand, the nominalist is convinced that reality cannot be reduced into its component parts, and that the world should be viewed as a "whole" that has a historical, social, and cultural context.

\section{Epistemology}

Epistemology revolves around knowledge, its nature, its forms, how it is acquired, and how it is communicated. The view that knowledge is hard, objective, and tangible will require an observing role from the researcher (2), and this would represent the positivist view. On the other hand, perceiving knowledge as personal, unique, and subjective, will require more involvement from the researcher, thus representing the anti-positivist, also called post-positivist view. From the positivist view, knowledge is made up of building blocks, adding new knowledge and knowledge patterns to old knowledge (7).

The philosophy of positivism emerged in the 19th century, and the person most responsible for the development and spread of this philosophy was Auguste Comte (1798-1857). Comte argued that the "positive" stage of human knowledge is reached when people rely on empirical data, reason, and the development of scientific laws to explain phenomena. Positivists believe that the scientific method is the surest way to produce effective knowledge (8). Foucault (9) argues that all knowledge and truth are products of history, power, and social interests and, hence, cannot be "discovered," as positivists believe. Therefore, postmodernists assume that the truth cannot be "discovered" but can rather be "generated".
Although positivism has changed somewhat over the years, a basic premise is that there exists a reality "out there," independent of us, waiting to be discovered, that is driven by stable natural laws. The task of science is to discover the nature of this reality and how it works.

It is obvious from the above discussion that methodological views will result from the researcher's perspectives concerning ontology, epistemology, and human nature. Therefore, if the researcher is adopting realism and positivism, they would tend to conduct experiments, surveys, etc. while the researcher who adopts nominalism and postpositivism, would tend to be more involved in their research, giving it a more humanly created nature.

\section{Methodology}

It is important at this stage to differentiate between the terms "methods" and "methodology". Methodology describes the approaches to, kinds and paradigms of research (10), while the methods are the tools used for data collection and that are used for inference and interpretation. Methodology refers to the theory of how inquiry should proceed, including assumptions, principles, and procedures governing the use of particular methods. Methods are the specific investigative tools or procedures used to gather and analyse data (11). It is obvious that methodology influences the choice of methods. However, methods should be seen as free from ontological and epistemological assumptions. The choice of methods should be decided in relevance to the research question.

\section{QUANTITATIVE AND QUALITATIVE RESEARCH IN EDUCATION}

\section{Origin}

Two paradigms emerged from the ontological, epistemological, and human 
nature views, namely the positivist paradigm and the naturalist paradigm. In positivism, a hypothesis is derived from theory and empirically tested and replicated by a researcher who remains neutral. Then, based on the result of a statistical hypothesis test, the researcher identifies the cause and effect relationship within a "value-free inquiry" (12). In this paradigm, the study hypothesis is either accepted or rejected and generalisation of results is possible. The positivist paradigm is believed to be the origin of quantitative research. On the other pole of the positivist paradigm, the naturalistic paradigm, which is also known as constructivism, emphasising on the role of the researcher in constructing meaningful knowledge. Qualitative research originated from this paradigm. From these views, we can see that the researcher can either adopt a deductive positivist paradigm and conduct quantitative research, or adopt a constructivist inductive paradigm and conduct qualitative research.

When researchers have little knowledge about new phenomena, qualitative research becomes essential for deep understanding of these phenomena. Quantitative research needs the guidance of qualitative research, either in generating theory, or in developing deeper understanding of some phenomena (13). Social scientists have been too quick to adopt the methods of natural science unquestioningly and have not given adequate recognition to the complexity of social situations, which are not necessarily reducible to a few numbers (7).

\section{Aim and Methodology}

Quantitative researchers base their work on the belief that facts and feelings can be separated, and that the world is a single reality made up of facts that can be discovered (8). In contrast to this view, qualitative researchers, assume that the world is made up of multiple realities, socially constructed by different individual perceptions of the same situation. What quantitative researchers are mainly seeking to achieve is to establish relationships between certain variables in a controlled setting, and probably also look for a cause and effect relationship among these variables, for the ultimate goal of generating laws that can be generalisable to the larger population. Qualitative researchers' aims are different, they are mainly searching for understanding more about situations from the viewpoint of the research participants, and without trying to control anything. Generalisation of laws does not represent a priority for qualitative researchers and is almost impossible to attain using qualitative research alone.

\section{Study Designs}

The quantitative research approach gives rise to many designs; experimental, quaziexperimental, and non-experimental designs. Each of these designs has types and processes. In experimental design, one group of individuals receives an intervention and another does not. Ideally, the two groups as matching so that the difference observed later would be attributed to the intervention. This is the most common design in quantitative research.

The qualitative approach gives rise to designs such as phenomenology, historical research, case study, ethnography, narrative research, grounded theory and action research. Phenomenology is the study of events from the perspective of each human being (14). Ethnography seeks to understand and explore members of a certain culture. Grounded theory is one of the proofs that qualitative research applies an inductive approach, whereas theory is generated from the phenomenon being investigated. In this design, people and how they communicate with each other is the main concern of the research. Case study is an in-depth analysis of one case; a class, a school, a patient, etc. Action research is a category that aims at producing change through research. 


\section{Role of Theory}

Quantitative and qualitative research approaches view theory differently. Qualitative research uses the inductive approach to explore the observed data for patterns and relationships, and then develops and tests hypotheses to generate theory. Therefore, in qualitative research, theory emerges from research work (15). In contrast to this situation, in quantitative research, hypothesis is deductively formulated from an existing theory, and then hypothesis is tested by data collection. Revision of the theory takes place according to the statistical results of research. In quantitative research, theory is essential for generalisation of results, while in qualitative research, a theoretical framework is only needed to organise dataset for interpretation, and the theory eventually originates from the research itself (16).

\section{Sampling}

When it comes to sampling, both quantitative and qualitative approaches use sampling procedures, but the aim and way of sampling differ greatly. The quantitative approach seeks a representative sample that has characteristics resembling the larger population from which the sample is drawn. Simple random sampling relies on known probability theory to establish a smaller group that represents the population, therefore generalisation can be made (4). In qualitative research, sampling is purposive not random and aims at covering a range of social phenomena from an appropriate array of sources (17).

Random sampling would be inappropriate for qualitative research for many reasons. Qualitative research tends to take small samples, which might generate large sampling errors, and in order for the sample to be representative, the research characteristics should be normally distributed among the population, which is not the case in qualitative research (18). Three sampling strategies were noted for qualitative research; convenience sample, judgement sample, and theoretical sample, in contrast to random sampling in quantitative research and its types; cluster, stratified, and systematic random samples.

\section{Process}

In quantitative research, first there is the identification of the research problem, then formulation of the research question and research hypothesis, then comes the review of literature, sampling, instrumentation, implementation, data analysis, interpretation of data, then accepting or rejecting the hypothesis aiming at generalisation of results to the population. In qualitative research, the process is the following: identification of the phenomenon to be studies, identification of the participants (including sampling), generation of propositions, data collection, data analysis, and then interpretations and conclusions (8). For quantitative research, the word "hypothesis" is usually mentioned, while is qualitative research, it is replaced by the word "proposition". Hypotheses in quantitative research are closely related to the research question and are predictions of what could be found in the results of the study, what relationships exist between the variables, and are usually stated at the outset as null hypothesis and alternative hypothesis. At the end of the study, the results and their interpretations will guide the researcher towards either accepting or rejecting the null hypothesis and possibly generating a law or relationship.

Hypotheses in qualitative research are formulated after the researcher has begun the study; they are grounded in the data and are developed and tested in interaction with them, rather than being prior ideas that are simply tested against the data. Propositions are the ideas stated at the beginning of qualitative research, and they differ from hypotheses in that they are flexible, discardable, and replaceable tools intended to help guide qualitative data collection and analysis.

From the difference in the process in both quantitative and qualitative research 
approaches, we can clearly explain the causes of these differences. Since quantitative research is based on deductive reasoning, it is logic to state hypotheses at the beginning of the study, while in qualitative research, which is based on inductive reasoning, the hypotheses comes from the study and can change according to what happens in the course of the study.

\section{Data Collection and Analysis}

In quantitative research, there is usually a "treatment" that is given to a certain group of people and not given to another group and the effects are measured on both groups whether a change took place. In educational research, the treatment is usually a course, a type of assessment, a new instructional method, etc. in qualitative research, there is no "treatment". The study participants are observed naturally as they function, teach, and assess students. Methods, or data collection instruments are quite different. While in quantitative research, selfadministered questionnaires, tests and data logs can be used, qualitative research tends to collect data through structured, semistructured, or in-depth interviews, focus groups, accounts, and observations. Record reviews can be applied in both approaches, according to what the researcher is looking for.

From the previous discussions about quantitative and qualitative research, we can predict that data analysis in quantitative research will be all about numbers and inferences drawn from those numbers; how much of a characteristic is present in the population, how many students liked the new instructional method, how many teachers used an assessment tool, how much this trait correlated to the other, etc. Data in quantitative research is seen as numbers, while in qualitative research, data analysis contains a considerable amount of description, with little presentation of numbers and percentages according to the phenomenon under investigation.
Quantitative research uses descriptive and inferential statistics to analyse data. Conclusions in qualitative research are formulated all along the study, while in quantitative research, they are usually left to the end after all data has been analysed and interpreted. Qualitative research applies the content analysis approach for data analysis, and recently, qualitative data analysis computer-assisted packages have been developed to help researchers in this difficult task.

\section{VALIDITY AND RELIABILITY}

Validity and reliability are important elements in the evaluation of any measurement instrument. Validity is concerned with the extent to which an instrument measures what it is intended to measure (15). It has many aspects that complement each other; face, content, criterion, and construct. Reliability is about reproducibility and internal consistency of the instrument (19). It is a statistical term that indicates the extent to which a measurement instrument consistently differentiates between individual subjects of interest (7).

In quantitative research, there are known methods for evaluating the validity and reliability of instruments. Many psychometric methods are used for this purpose; examples are the classic test theory, generalisability theory, and item response theory.

In qualitative research, these terms have been substituted with other terms that better describe the process, such as dependability, transferability, conformability, and credibility (20). Credibility refers to the "confidence in the truth value of the data and their interpretations". Confirmability is about the accuracy of the findings of the study which are based on the participants' viewpoints. Transferability is the substitute to generalisability in quantitative research and aims at identifying how well the findings of the study can be transferred to another 
setting, or another context. Dependability refers to the trustworthiness of the findings of the study.

\section{RESEARCH IN MEDICAL EDUCATION}

"The altruistic purpose of research in medical education is to deepen the knowledge and understanding of learning and education by studying phenomena, relations, and how and why what works for whom" (19). Through research, data is collected and analysed to better understand the teaching and learning process (21). A major challenge to medical education research is to place an idea of interest within a general context of learning, teaching, and education. In spite of concentrating on local problems, medical education research is more about researchable problems that might draw conclusions that can be generalised to the whole practice of medical education.

Ringsted et al. (19) developed a "research compass" that present an overview of the approaches to research in medical education. At the centre, they placed the conceptual theoretical framework, and then four categories constitute the compass. The first category is for explorative research, aiming at modelling, and comprises descriptive studies, psychometric studies and qualitative research approaches. The second category is the experimental studies, aiming at justification. The third category is observational studies, comprising cohort, case-control and association studies. Finally, translational studies represent the fourth category, focusing on implementation of knowledge from research in real life, which is similar to action research as described in social research literature.

Swanwick (7) suggests considering qualitative and quantitative research in medical education depending on "best fit" with purpose. Certain kinds of research questions are suited to certain paradigms, certain methodologies and methods, and that a dichotomous or hierarchical view may be severely limiting. Together, the components of a research paradigm should be congruent with the methodology.

Clinical educators feel less confident in the application of qualitative research approaches, as they think of research as having a large sample that is randomly taken from the population, with random assignment of the participants to either intervention or non-intervention groups (22). This could be due to that they prefer gathering empirical data grounded in objective, not subjective reality (23). In the respect, clarification on the responsibilities of medical educators versus medical educationists and medical education researchers needs to be made.

Medical educators are originally medical practitioners that practice medicine, teaching, and research. Not all of them have received formal training in education, not to mention educational research. Therefore, it would be understandable that they approach medical education research usually from the objectivist approach, perceiving the reality as "out there" and wanting to discover it. Medical educationists, on the other hand, are those medical practitioners who received training, and probably certification and degrees in medical education as a social science. Therefore, they assimilate the concepts of social constructivism, and are open to the idea of conducting qualitative research. This explains why in qualitative research is sometimes devalued in medicine, and is considered to be "subjective, biased, and opinion based" (24). Recently, the contribution of qualitative research in evidence-based practice is being recognised in both health care systems and medical education research (25).

In medical education, quantitative researchers criticised qualitative research vigorously. They argues that qualitative research did not have a strong design, and that for this reason, they would not recommend it for funding (26). They also awarded the highest level of evidence to quantitative research and they described 
qualitative research's quality as a "mystery" to health services researchers (27).

The aim of qualitative research is the development of concepts that help understand social phenomena in natural rather than experimental settings, while emphasising on the meanings, experiences, and views of the participants (28). Ringsted et al. (19) argue that quantitative and qualitative approaches are not opposing poles, rather they may be complementary ways of viewing similar phenomena. They elaborate that qualitative research in medical education can be used as a preliminary to quantitative research, as supplementary to quantitative research (in triangulation), or to explore phenomena not amenable to quantitative research. The contribution of qualitative research in best-evidence practices that inform decisions about teaching and learning, and also in health care has been recognised by many authors (25).

Qualitative research came to medical education in the 1980s from the social sciences and humanities, and that anthropology, sociology, education, and history used medical education as a site for research that shaped their own disciplinary questions and theories (7). Nowadays, medical education researchers use tools from these disciplines to solve problems arising in the domain of medical education.

\section{CONCLUSION}

Research is one way to understand the nature of phenomena. Educational research aims at benefiting and improving education. Assumptions about the social world, namely ontology, epistemology, human nature, and methodology, guide the conduction of research in education. Quantitative and qualitative research approaches differ in many ways; they differ in aims, origin, methodology, role of theory, process, sampling, methods, data analysis, and validity and reliability. It was long thought that they represent different paradigms that should never meet. Research in medical education started to consider qualitative and quantitative research approaches as complementary to each other depending on "best fit". Qualitative researches in medical education have, and still are benefiting the medical education field considerably.

\section{REFERENCES}

1. Mouly GJ. Educational research: the art and science of investigation. Boston, MA: Allyn \& Bacon; 1978.

2. Cohen L, Manion L, Morrison K. Research methods in education. 6th edition. London: Routledge; 2007.

3. Kerlinger FN. Foundations of behavioral research. New York: Holt, Rinehart \& Winston; 1970.

4. Horn C, Snyder BP, Coverdale JH, Louie AK, Roberts LW. Educational research questions and study design. Academic Psychiatry. 2009;33(3):261-67. https://doi. org/10.1176/appi.ap.33.3.261

5. Burrell G, Morgan G. Sociological paradigms and organizational analysis. London: Heinemann Educational; 1979.

6. Hitchcock G, Hughes D. Research and the teacher. 2nd ed. London: Routledge; 1995.

7. Swanwick T. Understanding medical education: evidence theory and practice. 2nd ed. London, UK: Wiley Blackwell; 2014.

8. Fraenkel JR, Wallen NE, Huyun HH. How to design and evaluate research in education. 8th ed. New York, USA: McGraw Hill; 2012.

9. Foucault M. The archaeology of knowledge. New York: Harper and Row; 1972.

10. Kaplan A. The conduct of inquiry. Aylesbury: Intertext Books; 1973.

11. Schwandt TA. The Sage dictionary of qualitative inquiry (3e). Thousand Oaks, CA: Sage Publications; 2007. https://doi. org/10.4135/9781412986281 
12. Denzin N, Lincoln Y. The discipline and practice of qualitative research. In: Denzin $\mathrm{N}$, Lincoln $\mathrm{Y}$, editors. The SAGE handbook of qualitative research. Thousand Oaks: Sage; 2011. p. 1-19.

13. Trice L, Bloom K. PICOT, problem statement, research question, hypothesis. In: Boswell C, Cannon S, editors. Introduction to nursing research. Burlington, MA: Jones \& Bartlett; 2014. p. 129.

14. Tavakol M, Sandars J. Quantitative and qualitative methods in medical education research: AMEE Guide No 90: Part I. Medical Teacher. 2014;36(9):74656. https://doi.org/10.3109/014215 9X.2014.915298

15. Morse J, Field P. Qualitative research methods for health professionals. Thousand Oaks: Sage; 1995.

16. Tavakol M, Sandars J. Quantitative and qualitative methods in medical education research: AMEE Guide No 90: Part II. Medical Teacher. 2014;36(10):83848. https://doi.org/10.3109/014215 9X.2014.915297

17. Giacomini MK, Cook DJ. Users' guide to the medical literature: XXIII. Qualitative research in health care $B$. What are the results and how do they help me care for my patients? Evidence-based medicine working group. JAMA. 2000;284(4):478-82. https:// doi.org/10.1001/jama.284.4.478

18. Marshall MN. Sampling for qualitative research. Family Practice. 1996;13:522-25. https://doi.org/10.1093/fampra/13.6.522

19. Ringsted C, Hodges B, Scherpbier A. "The research compass": an introduction to research in medical education: AMEE Guide No. 56. Medical Teacher. 2011;33:695-709. https://doi.org/10.3109/0142159X.2011. 595436

20. Lodico MG, Spaulding DT, Voegtle $\mathrm{KH}$. Methods in educational research: from theory to practice. 2nd ed. San Francisco, CA: Jossey-Bass; 2010.
21. Norman G. Research in medical education: three decades of progress. BMJ. 2002;324:1560-2. https://doi.org/10.1136/ bmj.324.7353.1560

22. Tavakol M, Murphy R, Rahemei-Madeseh $\mathrm{M}$, Torabi S. The involvement of clinicians in medical education research. Qual Prim Care. 2008;16:335-40.

23. Buckley G. Partial truths-research papers in medical education. Med Edu. 1998;32:1-2. https://doi.org/10.1046/j.13652923.1998.00187.x

24. Morse J, Dimitroff L, Harper R, Koontz A, Kumra S, Matthew-Maich N, Mihas PCM. Considering the qualitativequantitative language divide. Qual Health Res. 2011;21:1302-3. https://doi. org/10.1177/1049732310392386

25. Bower E, Scambler S. The contributions of qualitative research towards dental public health practice. Community Dentistry and Oral Epidemiology. 2007;35:161-9. https:// doi.org/10.1111/j.1600-0528.2006.00368.x

26. Morse J. Reconceptualizing qualitative evidence. Qual Health Res. 2006;15:859-60. https://doi.org/10.1177/1049732305279135

27. Dingwall R, Murphy E, Watson P, Greathbatch D, Parker S. Catching gold fish: quality in qualitative research. J Health Serv Res Policy. 1998;3:167-72. https://doi. org/10.1177/135581969800300308

28. Pope C, Mays N. Reaching the parts other methods cannot reach: an introduction to qualitative methods in health and health services research. BMJ. 1995;311:42-5. https://doi.org/10.1136/bmj.311.6996.42 